\title{
3 \\ ITINERANT \\ PHOTOGRAPHY: MEDIUM AND TRANSLATION IN THE WORK OF IMRAN CHANNA
}

\author{
Zahid R. Chaudhary
}

\section{Itinerancy}

It has become a truism for criticism on photography to note the relation photographs have to the past, or to analyse strange new temporalities that photographs make possible in their indeterminate position between imaging the past and being objects in the present. The aim, in any case, is to read photographs as forms of transmission: of a previous time into the present, of one part of the world appearing by means of reproduction in another part of the world. If Kant was correct in deducing that time and space - the axes of photographic transmission - are the categories of our understanding rather than objective conditions of the world we perceive, then photography bisects the very perceptual system (if you will) of our cognitive embeddedness in the world. Its proliferation in increasingly mobile forms - its quantitative increase - only deepens its qualitative effects. These effects are myriad, and in this short essay I will focus on two: photography's effects on the very notion of medium, and, connected to this, its effects on knowability.

These effects seem particularly heightened in the digital age but in fact have attended photographic practices since their inception in the nineteenth century. Approximately 200 years have passed since the invention of photography, long enough for the medium to become crystallized as one of the central forms in which the past is transmitted. I was led to reconsider photographic medium not in the conversion of photographs into digital data but in the decidedly analogue work of a contemporary Pakistani artist, Imran Channa. In a three-part series Channa renders iconic and non-iconic images of India/Pakistan partition into graphite drawings with obsessive attention to detail, resulting in an uncanny rendering of 
the familiar image in an aesthetic register that has converted the automatism of the camera's eye into an image touched in its most minute details by the artist's hand. The artist then proceeds to erase, smudge or redraw the image again, resulting in abstract forms that bear only the faintest resemblance to the original photograph. The work does far more than merely question the verisimilitude of photographic vision; it reorients our understanding of photography's place as a vehicle of the past's transmission and as a placeholder for ever-changing collective memory. It does so by relying on tendencies that have adhered to photographs since their invention. I will have much more to say about Channa's work, but in order to grasp its critical interventions we require a brief detour through the early history of photography in British India, a history that already demonstrates flexible tendencies at the heart of the photographic medium. These tendencies form the very groundwork for what I am calling photography's itinerancy.

Early photography wrought important changes in what we call medium, and also in what people came to consider as the knowable world. I will briefly note some of these changes and to do so I will shuttle across photography's early history in India and its contemporary circulation - in particular, from the work of nineteenthcentury photographer Linnaeus Tripe, to the work of contemporary Pakistani artist Imran Channa, who renders photographs into graphite drawings. With this juxtaposition I hope to open up some questions concerning photography's itineraries, and by 'itinerant photography' I mean to refer to several kinds of traffic: traffic between parts of the globe, between aesthetic forms, and between photography and other mediums. To do justice to these itineraries one has to disturb the very notion of 'South Asian photography'. After all, photographic practices everywhere articulate with local forms of representation, forms that modulate the alteration, distribution and cultural meanings of the photographs. How does one hold on to the historical specificity of South Asian photography (i.e. what Christopher Pinney once called Camera Indica)' and also keep in play the larger world-historical shifts in which the subcontinent is also enmeshed? The trade routes that stretched through the subcontinent had already made it, like many places in Asia, the product of constantly changing aesthetic and political influences. If one looks at the general arc of photographic history, from its early experiments, to its emancipation from those older forms of seeing, to its use in newspapers, its culturally mediated use in rituals and ceremonies, and now into the digital age, one has to concede that photography is, as a medium, highly elastic and flexible. It might well teach us that medium has its elastic and flexible aspects and it requires that our methods of interpretation shift with respect to such flexibility. When a photograph enters the newspaper, the newspaper becomes, in a certain sense, a part of its medium. If we conceive of medium as itself composed of historically accreted forms - because medium is never merely given, never purely natural - then one is forced, when interpreting photography, to keep in view the historically specific way in which matter becomes medium. 
It is because artistic mediums are so flexible that cultural and historical accommodations can be made even within photography; as a medium photography wends its way through constantly changing and contradictory forms of seeing, markedly attaching to itself cultural practices and forms of representation in its various global contexts. Such itinerancy creates entirely new genres and forms of looking that photography has made possible from its inception: from ethnographic photographs, to topographical views, the modern snapshot, the painted image, the devotional image and, of course, the selfie. Although these forms of cultural embellishments and accommodations are wondrous in their own right, they merely point to the general tendency of all photography itself: as a medium it is poised to disturb the contours of other mediums. For example, some early photographs from Lucknow show courtly figures embellished with inscriptions and miniature-style drawings; ${ }^{2}$ photographs in newspapers seek, by means of their visual rhetoric, to lend objective truth to the reportage and thereby change the nature of the newspaper; photographs inserted within modernist painterly experiments change the character of painting, etc. Surely none of this is news, but I am underscoring the plastic nature of medium in order to emphasize that our own methodologies for understanding photography require a similar pliability.

What I would like to explore is how one might attend - within the same method of interpretation - to two simultaneous facts: first, that photographs are conditioned by the political and historical circumstances that produce them on the one hand, and second, that photographs also bring into focus a whole host of insights, that, if too rigorously contextualized and historicized, risk becoming so qualified that their analytical charge becomes untranslatable to other contexts. This is to say that even as we historicize South Asian photography - its technomaterial realities, its forms of transmission, its culturally conditioned practices we must simultaneously allow our analyses a certain openness to overlapping contexts. Photography itself travels by means of reproducibility, and photographs come into encounters with unanticipated contexts. What might it mean to keep our analyses open to such itinerancy, an aspect of the medium itself? For one, it might imply that statements about South Asian photography are interesting not because they constitute, once again, a particularizing discourse about a regional photographic practice, but because regional practice itself has much to teach us about larger issues such as the claims of memory, truth, beauty or devotion, etc. Historicizing photographic practices in this way opens up regional specificity rather than particularizing it, both by understanding regional differences as being embedded in global social relations and by examining the unintended representational effects of photographic practices. As we will see, one of these unintended effects is on our very understanding of what counts as medium, and because of this, as a technology photography is poised to supply a unique form of translation, across geography and generations, but also across ways of knowing. 


\section{Medium}

Working at an early period of photographic practice, when photography held out the promise of scientific objectivity for some, and was a fertile field of aesthetic experimentation for others, Linnaeus Tripe produced a series of photographs documenting architectural sites. For a period of eight years, from 1852 to 1860, Tripe worked in the service of the British army as a photographer, documenting the Madras Presidency as well as sites in Burma. His expedition to Burma, in particular, was intended to gather information in the service of the colonial state's growing economic and political interest, as Burma would eventually be enfolded into direct colonial rule. Tripe's photographic projects were part and parcel of the familiar attempts at gathering knowledge about India - the colonial officials who hired him asked him 'to record accurately and in detail the historical monuments, geological features, botanical elements, and inhabitants of the country, together with their customs, dress, and occupations'. ${ }^{3}$ In other words, the primary importance of these photographs, from the perspective of the colonial state, was their indexical truth: that these antiquities and landscapes really did exist in this form.

Alongside this indexical function, Tripe's work also performs some aesthetic interventions: it continued the picturesque aesthetic, and it extended the medium of architecture itself. By the time Tripe took his picturesque scenes, the conventions of the picturesque were well established and already popularized. Tripe, like many of his contemporaries, hired assistants to retouch his photographs, adding picturesque elements like clouds, reflections and shadows. ${ }^{4}$ Here, the photographic medium readily meets the demands of picturesque conventions (Figure 3.1).

Anthropologist Nicholas Dirks has analysed Tripe's photographs as documents of a certain colonial loss: they invoke the usual colonial nostalgia for an ancient Eastern civilization even as they record, almost in spite of themselves, the transition within the colonial order marked by the 1857 rebellion. ${ }^{5}$ This rebellion was a critical shift in colonial governance in India since the rule of the East India Company was replaced with the direct Crown rule. This meant that the princely states in India gradually became mere theatrics dependent on the British largesse. Tripe's photographs are situated at this historical transition. They invoke, in their subject matter, the mystery of great civilizational loss, the fall from grace of an ancient civilization. The picturesque embellishments - the darkening of shadows, the deepening of cloud forms - bring out the melancholia latent within the picturesque tradition all along, especially its obsession with ruins. Even when Tripe recorded ancient buildings still in use, his photographs show them as vacant and unpeopled.

Tripe was particularly drawn to photographing architectural sites. Architecture, perhaps more than landscapes, lent itself to photographic technology at this time by the sheer fact of its stillness. And yet the medium of architecture requires 


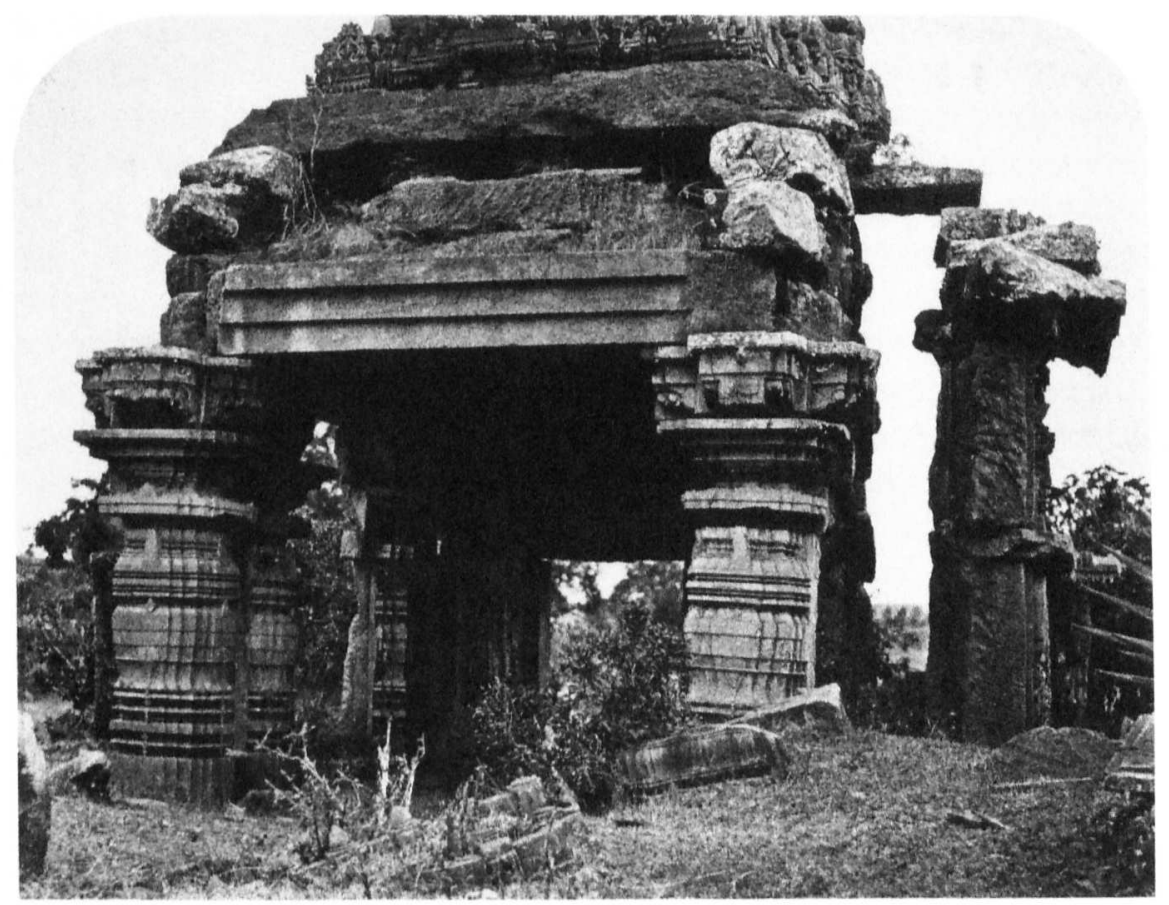

Figure 3.1 Linnaeus Tripe. Hullabede: Suli Munduppum from the Northeast, December, C. 1854 .

a bodily relationship to the space as organized by the building. Tripe's medium cannot possibly approximate architecture, but I would like to speculate here about the elasticity of artistic medium and note that if Tripe relies on the flexibility of photography as a medium, his photographs also point to a certain flexibility of architecture itself. Here it would be useful to be reminded of a term from literary studies, ekphrasis, which refers to poetry or prose that takes up an object as its concern and describes and meditates on it. Ekphrasis comes from the Greek words ek, meaning 'out of', and phrasis or 'speech'/'expression'. The most famous example of this is, of course, John Keats's poem 'Ode on a Grecian Urn'. The wonderful and mystifying character of ekphrastic expression is that the object that is rendered into language might be imaginary or it might be a real object. Even if it were a real object witnessed by the writer, its conversion into language makes it imaginary for the reader. ${ }^{6}$ The ekphrastic object is necessarily ambiguous - whether it is something found by the writer or created by the writer is beside the point. It is, in a deep sense, both found and created. My account of ekphrasis borrows from psychoanalyst D. W. Winnicott's definition of the transitional object, which for the child is often an object of play: 'Of the transitional object it is a matter of agreement between us and the baby that we will never ask the question: "Did you conceive of this or was it presented 
to you from without?" The important point is that no decision on this point is expected. The question is not to be formulated'? The ekphrastic object is akin to the object of play because it is invested with a certain libidinal energy and is a means for traversing the boundaries between the child and the world, including its objects and people. It is, in short, across such transitional objects that the relations between me and not-me crystallize.

My wager is that all photographic images inhabit this ambiguous representational state of which ekphrasis is a figure, naming an age-old itinerant tendency at the heart of representation itself. Photographs are forms in which the world has revealed itself and yet they are also conjurations and productions. It is not at all accidental that Walter Benjamin designated play as the twin of semblance: all forms of mimetic practice involve, in his understanding, a distribution across play and semblance. Notions of semblance have a commonsensical appeal to our understandings of photographs because they seem (at least on the surface) to address the symptomatic discourses about photography's objectivity or its lack thereof, or its indexical truth or aesthetic intervention. The play aspect of photographs often eludes our gaze and has to be read back into critical histories of photography. This aspect itself opens up a field of critical questioning because as a term it has a neutral charge, much like semblance. It points in the direction of greater critical attention to experimentation, improvisation, contingency, anachronism, creativity and the production of the wholly new. It also evokes non-instrumentality, purposiveness without purpose (Kant's classic definition of beauty) and transformation. It represents, in other words, a dynamic field of practice that concern with semblance can often overlook. For my purposes here I isolate this particular and paradoxical character of the object of play: its status as both found and created.

This is how one might understand Tripe's architectural photographs: the buildings are found by him in the real world of nineteenth-century India and Burma, and yet they are also conjured by him. The photographs are objective records and yet they enframe and interpret at the same time. These two aspects of photography are not in conflict but the photographs themselves are evidence of this paradox. Architecture as a medium has its photographic aspect, and it would be a reduction to assume that architecture as a medium is only to be authentically experienced in person. Tripe's photographs translate architecture into photography. His architectural photographs are ekphrastic translations, and like all translations, this one adds something to the original: it adds to it an element of indexical truth, that is, of the building really having been there at that time. These buildings really did exist in this state when Tripe photographed them; and yet these buildings ceased to exist in precisely this form immediately after being photographed. The photograph makes time itself the focus of our gaze, drawing out an element in the life of buildings that might otherwise be ignored. It draws out what might be communicable in the past. In Tripe's photographs, the 
time that enters our experience of this architecture is Tripe's own historical era, a sense we might not experience if we visited one of these buildings today. As we contemplate the ancient value of these architectural wonders, the photographs remind us that this value is one that has been transmitted by a more recent past. The photographs become one among other forms of this cultural transmission; their reproducibility makes the objects within the frame commutable across both time and space. Finally, as with any photograph, the time of viewing, too, becomes a part of the photographed object's history, and the photograph's own history (all photographs refer to two objects simultaneously: the image photographed and the photograph itself).

\section{Translation}

This way of conceiving photography and its travels is indebted, of course, to Walter Benjamin, who not only sought to rip objects of study out of their contexts in order to see them in a fresh light, but also analogized such flashes of insight with the reading of non-sensuous correspondences in the world and its received traditions. In 'Task of the Translator' Benjamin writes, 'just as the manifestations of life are intimately connected with the phenomenon of life without being of importance to it, a translation issues from the original - not so much from its life as from its afterlife' ${ }^{8}$ The manifestations of life bear a connection to life itself but in themselves are not of importance to it. What are photographs but one aspect of the manifestations of life, and while photographs bear a connection to how life might be lived, in themselves they are not critical to it. This analogy between translation and photography is not far-fetched if one considers the itinerary of truth in Benjamin's corpus: it appears in the early essays in the form of 'god's word', a nonsensible intention that runs through all languages and that translation reveals but only partially; in the later essays truth is the historical possibility created by visual technologies itself, both in the flashes of contingent insights that technological reproducibility makes possible and moments of danger in which thought must rescue cultural inheritance from the historical narratives that entrap it. Photographs bear a relationship to truth but not in the positivism of their indexical rhetoric, but in the intentionless manner in which the indexical is subject to resignification. All photographs might well be translations in Benjamin's sense in that they reveal, however partially, hitherto unforeseen aspects of the world, and make those aspects durable. This is why Benjamin specifies that 'a translation issues from the original - not so much from its life as from its afterlife'. ${ }^{9}$ When the photograph is read in a new context, its content might finally be grasped, perhaps for the first time.

So translation illuminates the original, and does not simply replicate it. Yet such illumination is hardly a guarantee, and visual technologies are remarkably 
capable of impeding insight. This is the case not only in straightforward ideological manipulation of visual technologies but in the unintended cases too where a certain photograph becomes so iconic that its meaning is covered over by its iconic charge. Sometimes replication dissembles the original even while transforming it. Consider how technological reproducibility has extended and transformed the afterlife of certain originals: Eisenstein's representation of Lenin has supplanted the image of the original figure himself, the infinite number of identical snapshots taken at the Taj Mahal and other auratic tourist sites make the photographs the referent for the sites themselves, the grainy and iconic images of nuclear explosions signifying the atomic age, concealing as much as they reveal, etc.

Once an image becomes iconic, that is to say, once it becomes shorthand for an entire set of associations, a historical narrative, a mark of the zeitgeist, or whatever, it veers away from revelation and becomes opaque once again. This is a special kind of opacity: rather than the generative opacity of having come to the limits of knowledge (the opacity of the unthought), this opacity is the result of an overabundance of meaning, and not just any meaning but an inchoate and collective meaning already agreed upon. Without the collective aspect of meaning making an icon can hardly be called an icon, and yet the mystery that resides in the heart of the iconic image rests there not because it is out of collective reach, but because the sheer multiplicity of collective meanings has installed it there. The afterlife of iconic images - their transmission across time and space - ensures that any insight to be gleaned from the image is foreclosed by inherited narratives surrounding the image, a kind of collective noise. In other words, the very flexibility of the medium can risk impeding translation. Iconic images, freighted and overdetermined, travel widely but might not quite be 'seen' since so many fragmented narratives and libidinal investments render them hyper-visible and simultaneously opaque. The data ratio of well-known images is transmitted alongside all this noise. How to attend both to this collective noise and to the past (already lost) that the image referenced?

This is among the questions posed by Imran Channa in his tripartite series, entitled Error, Erasure, and Memories. Each series takes up the problem of iconicity from a different angle. The artist's source materials for Error and Erasure are iconic photographs of the partition taken by photographers such as Henri Cartier-Bresson, Margaret Bourke-White and Bert Hardy. In the Memories series the artist mixes the iconic images of this historical catastrophe with the source material of his own personal photographs taken around Lahore and Shikarpur. Many of the iconic images of the partition were originally published not in South Asia but in magazines such as LIFE, which sponsored Margaret Bourke-White's partition series. As in Tripe's case in the nineteenth century, the production of 'South Asian photography' continues to occur by means of complex geopolitical systems of economic patronage, news reportage and the demands of an already- 
globalized audience. Channa's three series are composed of process work - that is, the series might result in particular pieces, but the artworks' unique form of abstraction and also realism makes sense only when one considers the artist's process for each series (Figure 3.2).

In Error, Channa painstakingly reproduces an iconic image from the partition as a graphite drawing, and then smudges the drawing in arc-like formations (Figure 3.3). In some of the pieces one can still see the lingering traces of the

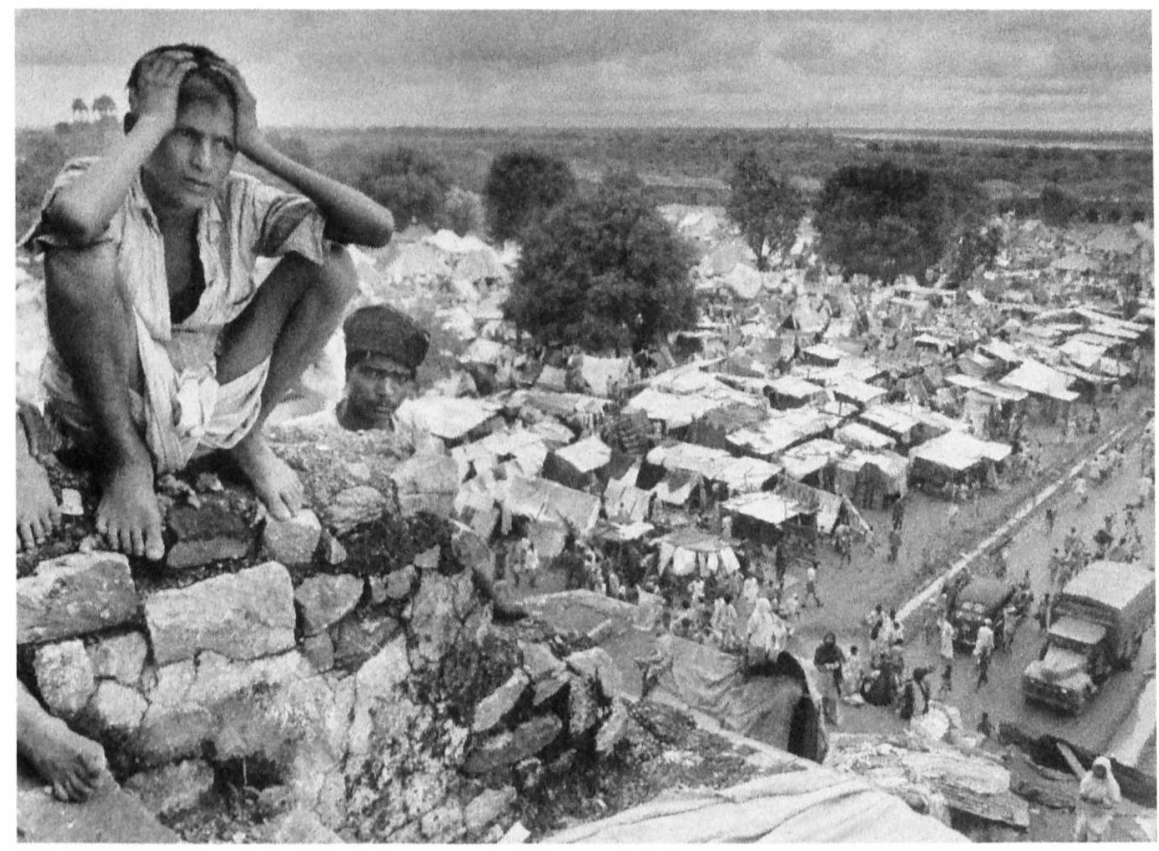

Figure 3.2 Margaret Bourke-White. October 1947: Boy sitting on rock ledge above refugee camp, c. 1947. Courtesy of The LIFE Picture Collection/Getty Images.
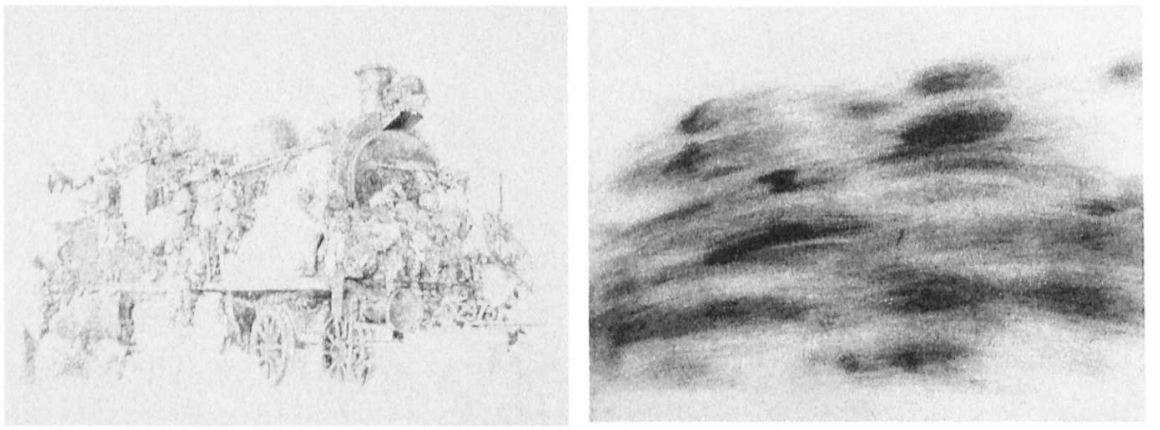

Figure 3.3 Imran Channa. Error I (work in progress on left, finished work on right), c. 2015. Courtesy of the artist. 
original image but these are overtaken by the signs of being crossed out and smudged. Art historian Iftikhar Dadi has pointed to the manner in which the original drawing, sometimes faintly visible is interrupted by and also interrupts the smudges that spread across the paper, noting a 'sensation of profound tension between abstraction and realism'. ${ }^{10}$

In Erasure on Paper, the graphite drawing based on original photographs is almost completely erased, with perhaps a section here or there still showing some original details (though smudged). The human figures in these drawings, and even the landscapes, seem uncanny in the originary sense of the word: both familiar and made foreign, like a memory on the cusp of recall. All that remains of the historical event is a trace, and though this trace is borrowed from the photograph, it has another nature entirely: it is that trace stripped of its iconicity, as if one were struggling to arrive once again at a familiar sense of an event but is continually faced with its radical alterity from what one thinks one knows (or can recall). When iconic images become anamnesis, this work suggests, we become dangerously certain of what we think we know (Figure 3.4).

The final series, Memories, extends this meditation deeper towards the opaque and the unknown. Once again Channa renders the original photograph into a graphite drawing with obsessive faithfulness, but now the work is smudged laterally in one direction and then another, creating evenly spaced striations across the page. After the work has been smudged entirely, the artist once more draws the same drawing over the smudged image, then smudges it again. The resulting series produces a set of dark opaque drawings that look both abstract and photographic. The source image is still visible but only in its transformation - smudged but with a finely grained sense of order and regularity. As Dadi remarks, 'this tension between the regularity of the striations and the primeval organic shapes of the massed forms can be allegorized as the tension of the individual lives that are caught up in modern ideological regimes that grind on, and the gyres of history continue to turn ceaselessly, over the bodies and lives of individuals and communities'. ${ }^{11}$ Since the artist included his own personal photographs as some of the source material that, in the final series, becomes impossible to tell apart from the iconic source material, it suggests that the collective meaning making of historical events and the distortions created by means of such narratives are of a piece with personal recollection (Figure 3.5).

These three inter-related series ask us to consider what it might mean to search for the truth of the historical catastrophe of the partition today when its history is received through photographs and narratives that have already become familiar and were probably always forms of conjuring. The partition continues to haunt the subcontinent not only because of the geopolitical interests that became crystallized in ongoing political and economic contestation, but also because the narratives and meanings of the iconic images remain uncertain, while national historical accounts remain self-interested. These artworks, by translating 


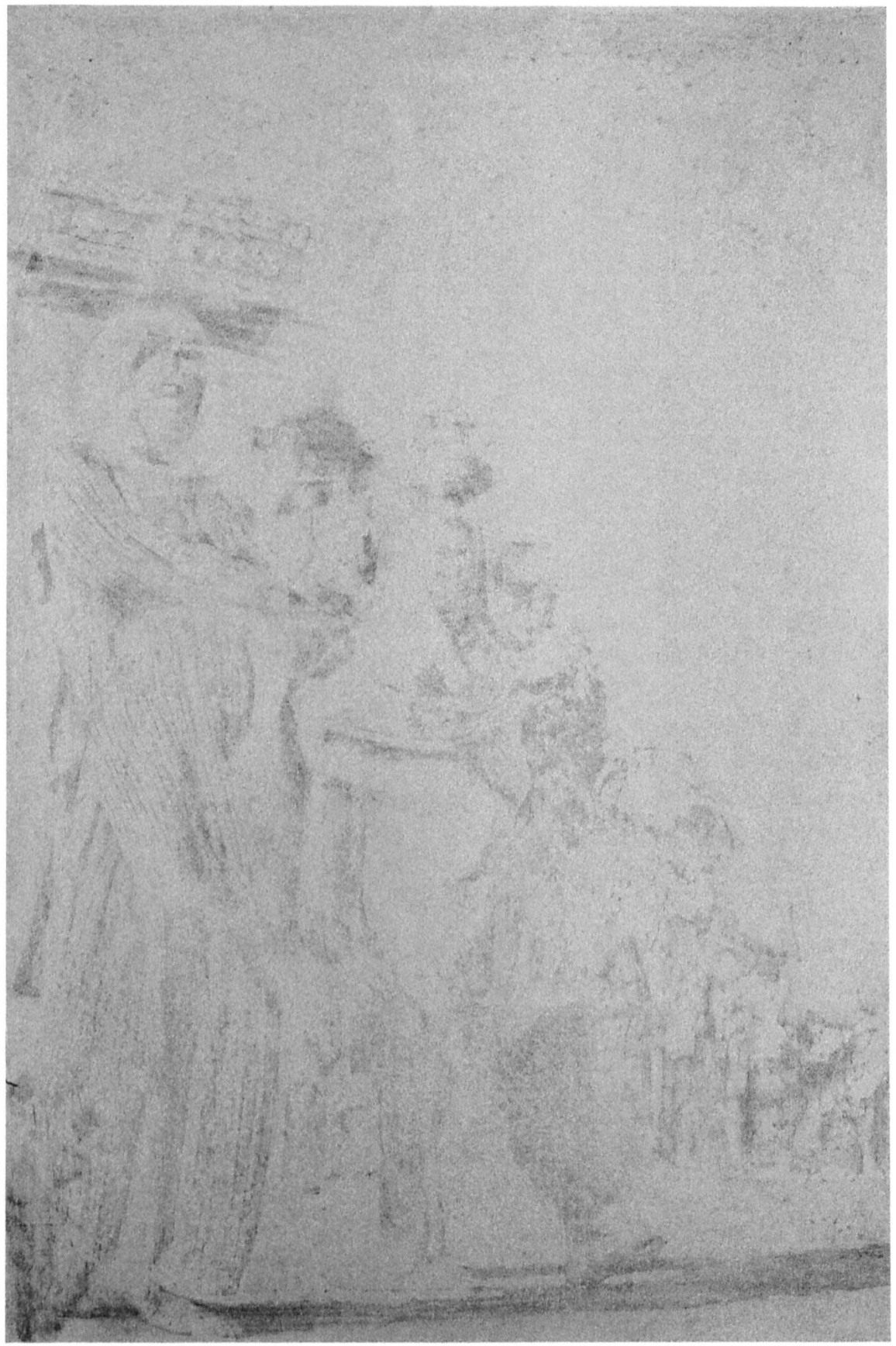

Figure 3.4 Imran Channa. Erasure on Paper I, c. 2015, Graphite on Paper, $52 \times 35$ inches. Courtesy of the artist. 


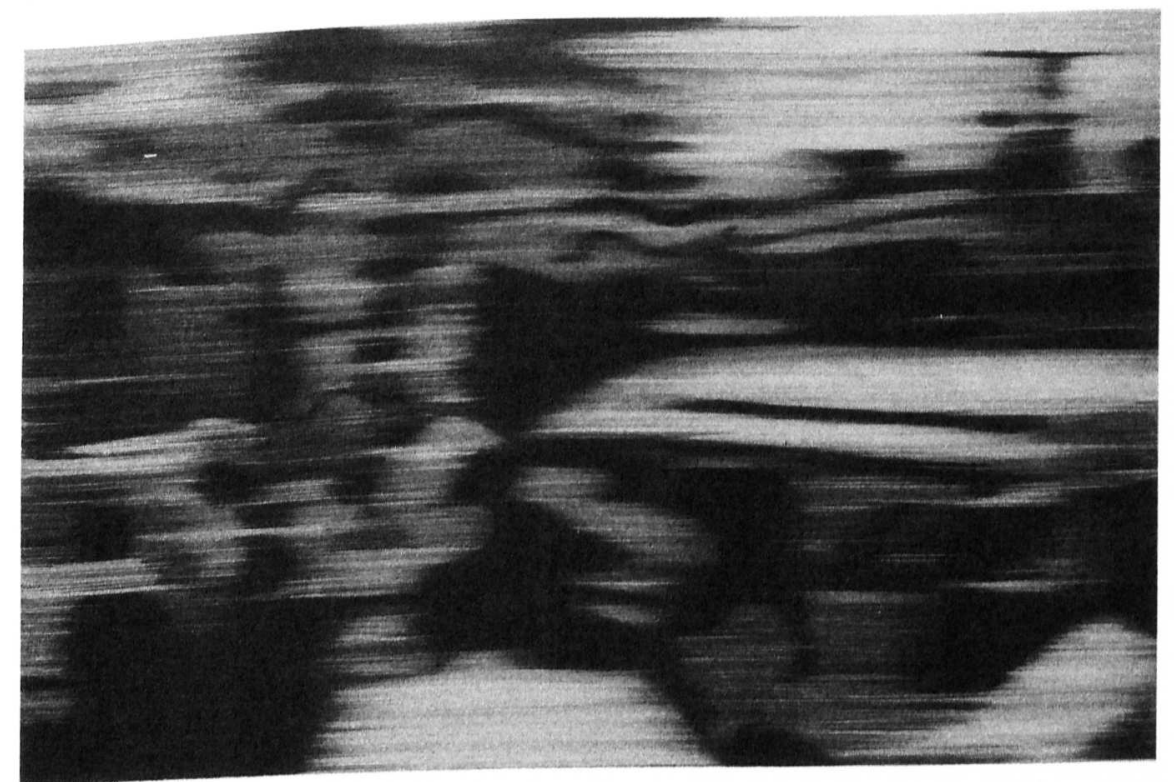

Figure 3.5 Imran Channa. Memories, Series. 2015. Graphite and erasure on paper. 29 $\times 43$ inches. Courtesy of the artist.

photography into another medium, offer up an entirely novel kind of evidence: the inheritance of a tradition whose meaning remains uncertain, and also the disturbance of representation in our memories and received histories. Each series insists on the centrality of the original photographic referent, painstakingly making the presence of the event appear as the condition of representation, but not selfevidently so. Memories, in its evenly spaced striations retains the character of technologically reproduced images, but now rendered almost entirely opaque. In a political climate where the afterlife of the partition continues to unfold, and in which all sides place stakes on their own tendentious accounts of its history, Channa's work provides the kind of illumination that Benjamin valorized: in some historical circumstances the truest insight is to adduce evidence of blindness, distortion and the grinding of individual lives into opacity.

Note how the indexical trace continues to operate in Channa's work, but not in any literal sense: redrawing the photograph by hand bears a relationship to the indexical trace but is not the same as an indexical trace. How might we read this gesture back into the history of South Asian photography? Recall that Tripe's photography, as a form of ekphrasis, was already situated somewhere between conjuring and reportage, all the while translating architecture into photography, revealing aspects of architectural experience specific to photographic vision. We discover new phenomenological aspects of architecture as a result of photography, and from this vantage point the two mediums interpenetrate. Such malleability of medium can be traced in other early photographic practices, from 
spirit photography to the photographic still life to the photographically based drawings in newspapers. The forms of medium flexibility that Imran Channa deploys in his artwork extend back into the earliest days of photographic practice. And yet more than this, Channa's work suggests that such malleability of medium might well rest on age-old practice of reading correspondences in the world. By rendering iconic photographs into their corresponding drawings and then erasing, blurring or grinding down the representational links between the overly voluble iconic image and its copy, Channa foregrounds the practice of reading itself. The icon becomes enigma, or, more accurately, is translated into one. The past event reveals itself to be less easily known than we had expected, and, in turn, our forms of reading reveal their limits.

Imran Channa's work points to another kind of contingency that always lurked at the heart of the photographic index: in addition to pointing to the unseen, the as-yet-to-be-unconcealed in every photograph, this contingency points to the possibility that nothing might finally reveal itself, or that revelation might yet take the form of opacity. If the glimmer of truth is partially visible by means of translation, there still remains that which cannot be communicated, and holding fast to this incommunicability might well be the critical move that preserves history from lapsing into narratives that serve the present status quo. Marking such moments of opacity would mean to begin to make inventory of the losses incurred in the traffic of inherited traditions. The malleability of medium is the condition of the past's translation, not its result, and Channa relies on the malleability of photographs, that is, their itinerancy, and plays with their form of semblance and correspondence, in order to remind us of the histories to which photographs are never adequate.

\section{Notes}

1 Christopher Pinney, Camera Indica: The Social Life of Indian Photographs (Chicago: Chicago UP, 1997).

2 See further discussion of such photographs in Zahid Chaudhary, Afterimage of Empire: Photography in Nineteenth-Century India (Minneapolis: Minnesota UP, 2012), 131-139.

3 Janet Dewan, 'Linnaeus Tripe: Critical Assessments and Other Notes', The Photographic Collector 5, no. 1 (Fall 1984): 49.

4 For further discussion of Tripe's innovative retouching and alteration techniques, see 'Captain Linnaeus Tripe: Photographer of India and Burma, 1852-1860', Exhibition Catalogue. Washington DC: National Gallery of Art, 2015, especially pp. 5-48: 'The Pioneering Photographic Expedition of Linnaeus Tripe' by Roger Taylor.

5 Nicholas Dirks, 'Colonial Amnesia and the Old Regime in the Photographs of Linnaeus Tripe', in Traces of India: Photography, Architecture, and the Politics of Representation, ed. Maria Antonella Pelizzari (New Haven, CT: Yale UP, 2003), 197-216. 
6 For an account of ekphrasis in relation to photography, see Andrew D. Miller, Poetry, Photography, Ekphrasis (Liverpool: Liverpool UP, 2015).

7 D.W. Winnicott, Playing and Reality (New York: Routledge, 2005), 17.

8 Walter Benjamin, Selected Writings Vol. 1: 1913-1926 (Cambridge, MA: Harvard UP, 2000), 254.

9 Ibid.

10 Iftikhar Dadi, 'Spectral Memories', in Exhibition Catalogue of 'Enclosure/Erasure' (Karachi: Koel Gallery, 2015).

11 lbid.

\section{Select Bibliography}

Benjamin, Walter. Selected Writings Vol. 1: 1913-1926. Cambridge, MA: Harvard UP, 2000.

Chaudhary, Zahid. Afterimage of Empire: Photography in Nineteenth-Century India. Minneapolis: Minnesota UP, 2012.

Dadi, Iftikhar. 'Spectral Memories'. In Exhibition Catalogue of 'Enclosure/Erasure'. Karachi: Koel Gallery, 2015.

Dewan, Janet. 'Linnaeus Tripe: Critical Assessments and Other Notes'. The Photographic Collector 5, no. 1 (Fall 1984).

Dirks, Nicholas. 'Colonial Amnesia and the Old Regime in the Photographs of Linnaeus Tripe'. In Traces of India: Photography, Architecture, and the Politics of Representation, edited by Maria Antonella Pelizzari. New Haven, CT: Yale UP, 2003.

Miller, Andrew. Poetry, Photography, Ekphrasis. Liverpool: Liverpool UP, 2015.

Pinney, Christopher. Camera Indica: The Social Life of Indian Photographs. Chicago: Chicago UP, 1997.

Taylor, Roger, Crispin Branfoot, Sarah Greenough and Malcolm Daniel. Captain Linnaeus Tripe: Photographer of India and Burma, 1852-1860. London: Prestel, 2014.

Winnicott, D.W. Playing and Reality. New York: Routledge, 2005. 